\title{
Violencia hacia la vida. Gubernamentalidad y pobreza urbana
}

Luciano Martín Mantiñán

Doctor en Antropología Social y licenciado en Antropología Social y Cultural por el Instituto de Altos Estudios Sociales, Universidad Nacional de San Martín. Becario posdoctoral CONICET. Coordinador y docente de la cátedra intensiva de vicerrectorado "Cómo hacer investigación" y miembro del LICH (Laboratorio de investigaciones en Ciencias Humanas) Escuela de Humanidades, Universidad Nacional de San Martín.

lmmantinan@yahoo.com.ar

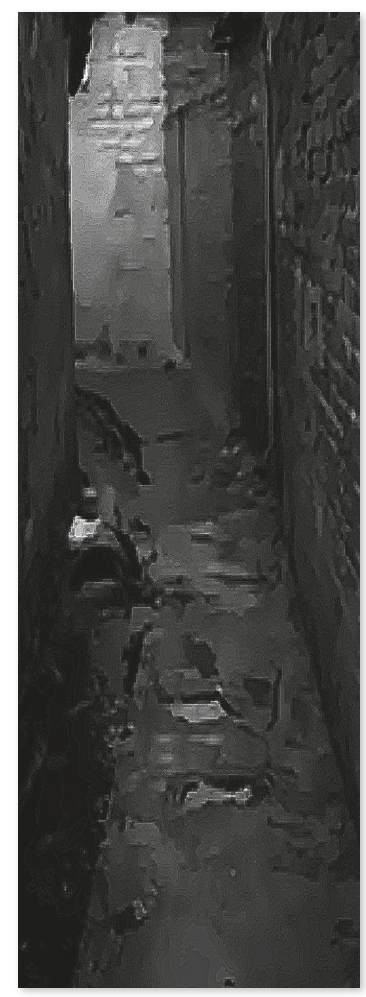

$10.30972 / \mathrm{crn} .28284324$ ISNN 1666-6186. Volumen 28 N. ${ }^{\circ} 28$ (junio de 2020) Pp. 059-077 - Recibido: 12-04-19. Evaluado y aprobado: 28-02-20 


\section{Violencia hacia la vida. Gubernamentalidad y pobreza urbana}

\section{Resumen}

El artículo presenta resultados de investigación etnográfica acerca de algunas de las particularidades que presentan las políticas sobre la vida en aquellos barrios comúnmente conocidos como "villas miseria". Se trata de un trabajo de investigación desarrollado entre los años 2014 y 2017 en la región metropolitana de Buenos Aires, más específicamente en José León Suárez. Se focaliza en el análisis de situaciones y acontecimientos que expresan una modulación de la vida en las villas, que proponemos denominar como violencia hacia la vida en contextos de extrema pobreza urbana y degradación ambiental. Analizamos las tensiones que adquieren estas situaciones, entendiendo que constituyen una parte clave de la trama del gobierno y las lógicas de poder tal como se ensamblan cotidianamente en estos barrios de la urbe metropolitana, dinámicas del poder que rebasan dichos espacios urbanos y forman parte de los modos que asumen las políticas sobre la vida en las metrópolis contemporáneas.

\section{Palabras clave}

Violencia; pobreza; degradación ambiental; gubernamentalidad.

\section{Violence towards life. Governmentality and urban poverty}

\section{Abstract}

The article presents result of an ethnographic research about some of the particularities that life policies present in those neighborhoods commonly known as "slums". This is a research work carried out between 2014 and 2017 in the metropolitan region of Buenos Aires, more specifically in José León Suárez. It focuses on the analysis of situations and events that express a modulation of life in the villages, which we propose to call violence towards life in contexts of extreme urban poverty and environmental degradation. We analyze the tensions that these situations acquire, understanding that they constitute a key part of the government's fabric and the logics of power as they are daily assembled basis in these metropolitan neighborhoods, power dynamics that go beyond these urban spaces and are part of the ways that policies on life assume on contemporary metropolises.

\section{Keywords}

Violence; poverty; environmental degradation; governmentality

\section{Violência para a vida. Governamentalidade e pobreza urbana}

\section{Resumo}

0 artigo apresenta resultados de uma pesquisa etnográfica sobre algumas das particularidades que apresentam as políticas sobre a vida naqueles bairros comumente conhecidos como "favelas". Trata-se de um trabalho de pesquisa desenvolvido entre os anos 2014 e 2017 na região metropolitana de Buenos Aires, mais especificamente em José León Suárez.

Concentra-se na análise de situações e eventos que expressam uma modulação da vida nas vilas, que propomos denominar violência para a vida em contextos de extrema pobreza urbana e degradação ambiental. Analisamos as tensões que essas situações adquirem, entendendo que elas constituem uma parte essencial da trama do governo e da lógica do poder à medida que encaixam diariamente nesses bairros da cidade metropolitana, dinâmicas de poder que vão além desses espaços urbanos e fazem parte dos modos que as políticas de vida assumem nas metrópoles contemporâneas.

\section{Palavras chave}

Violência; pobreza; degradação ambiental; governamentalidade. 


\section{Antecedentes y contexto}

Los barrios populares que comúnmente suelen ser llamados "villa miseria"1 remontan su creación a las primeras décadas del siglo XX, al compás de los procesos de industrialización y migraciones hacia la urbe. Como señala RATIER (1985), los espacios urbanos conocidos como "villas" han crecido al calor del quiebre en los términos del intercambio -exportación de materias primas, importación de manufacturas-, que tanto había favorecido el desarrollo del país en épocas anteriores. Aquel quiebre tendrá como consecuencia la primera expansión de la industria nacional, que buscará sustituir las importaciones que se habían vuelto más caras y en algunos casos inaccesibles (ToRre y PASTORIZA, 2002).

Las principales ciudades del país, con Buenos Aires como caso arquetípico, crecen al compás de la industrialización y se transforman en el foco de las esperanzas de los grupos de personas expulsados del campo (Romero, 1986). La villa nace así como una extensión de la ciudad, cercana a las únicas fuentes de trabajo para una población empobrecida y desplazada. La situación va a ver drásticamente agravada a partir de los años 70 del siglo anterior, cuando las villas comienzan a crecer a un ritmo tan constante como traumático, en tanto en este período espacios que estaban "vacíos” y constituían bañados, totorales, terrenos escasamente poblados se transformaron en espacios densa y aceleradamente poblados (MERKLEN, 2005; CuRutChet, GrinberG, GutTí́RREZ, 2012).

El Partido de General San Martín, municipio del área metropolitana de la provincia de Buenos Aires, que es objeto de este estudio, es un claro ejemplo de estas transformaciones territoriales y sociales. Fundado en 1856 como una localidad agrícola-ganadera, se convierte en ciudad con el crecimiento del modelo industrial en el país. Estas industrias en las últimas décadas del siglo XX sufrieron los procesos de deterioro y abandono mencionados anteriormente (PrĖVôt SCHAPIRA, 2001; AuYERo, 2001). Este proceso de desindustrialización condujo de un modo inevitable al desempleo y la pauperización de grandes estratos de la población. A los antiguos barrios obreros, desde fines del siglo XX en proceso de precarización paulatina, se sumaron los asentamientos y villas, que crecieron, en tamaño y cantidad de habitantes, de modo exorbitante y constante.
1. El término "villa miseria" fue acuñado por el periodista Bernardo Verbistsky en su novela Villa Miseria también es América (1957), en la que se realiza una descripción de las condiciones de vida de los inmigrantes durante la Década Infame. Luego es HUGo RATIER (1985) quien se ocupa de rastrear el origen de estas en nuestro país, dando cuenta del complejo proceso que se inicia con el cambio en la economía durante las primeras décadas del siglo XX. 
El trabajo en terreno de esta investigación se realiza entre los años 2014 y 2017 en algunos de los barrios ubicados sobre la cuenca hidrográfica del río Reconquista en el Partido de General San Martín, cuyo surgimiento y crecimiento se encuentra estrechamente ligado a estos procesos históricos y sociales mencionados.

En este artículo nos referimos a situaciones de vida que atraviesan a las metrópolis del sur global, en torno de las cuales - y retomando a ARABINDOo (2011) - se ha configurado una retórica de los slums, retóricas que resaltan las situaciones de criminalidad, violencia y degradación como lo propio de estos espacios urbanos (DAVIES, 2007; AuYERO y BERTI, 2014; LEWIS, 1983; SchePER-Hughes, 1993). Ahora bien, más allá de esa retórica y como resultado del trabajo etnográfico en terreno, proponemos la noción violencia hacia la vida como un modo de acercarse a la comprensión de los modos políticos de esa violencia, desde una perspectiva específica: la experiencia de esa violencia, cómo es vivida y significada por los mismos sujetos. Es en este marco - como se tratará de esclarecer en este artículo- que se vuelve clave comprender estos procesos atendiendo a las lógicas de poder que los atraviesan en el marco de la urbe metropolitana (Prèvôt Schapira, 2001; Osborne y Rose, 1999; Grinberg, GutiéRREZ Y MANTIÑÁn, 2012).

El estudio de las experiencias de violencia y sus significados es, desde ya, una cuestión compleja, como señalaron diversos autores (GarRiga Zucal y Noel, 2010; Bourgois, 2002; Bermúdez, 2008), principalmente por dos factores fundamentales. En primer lugar, la diversidad de episodios que se podrían incluir en la categoría de experiencias de violencia es muy amplia. Por otra parte, los significados asociados a dichos episodios no son inequívocos, y es probable que sus valoraciones puedan ser muy disímiles. Consideramos que un punto de partida relevante para comenzar a asirla lo constituye el trabajo de campo etnográfico. En este artículo nos enfocamos en rastrear cómo aparecen estas situaciones significadas en los relatos y experiencias personales de los sujetos implicados. En la analítica de esos episodios, recuperamos aspectos en los cuales esa experiencia de la violencia forma parte de las particularidades que asume la gestión política de la vida urbana.

A los efectos de esta presentación, hemos organizado el trabajo del siguiente modo: por un lado, en el siguiente apartado se realiza una breve introducción conceptual al problema; esto permitirá encuadrar nuestra concepción del fenómeno estudiado dentro del campo de los estudios sobre esta temática. Al mismo tiempo, esa problematización conceptual involucra 
la construcción metodológica de esta investigación. En la segunda parte del artículo, la más extensa, nos dedicaremos justamente a presentar y analizar algunas de las significaciones y episodios que la categoría violencia hacia la vida procura describir y problematizar. Para el caso de este artículo, nos focalizaremos en dos situaciones/tópicos, que consideramos de particular relevancia en lo que hace al estudio del fenómeno de la violencia en estos espacios urbanos: la experiencia de la violencia asociada al propio espacio material de la villa y la muerte violenta en particular de jóvenes².

\section{Recorrido conceptual y metodológico}

El estudio etnográfico de la violencia presenta enormes desafíos que involucran la pregunta respecto de cuándo los eventos pueden ser nombrados como tales (DAs, 2003). Como lo señala la autora referenciada, se trata de prestar atención a la experiencia de la violencia tanto como a las formas en que esa experiencia se vuelve cognoscible y, por tanto, narrable. Ello teniendo una doble visión que implica detenerse, por un lado, en las formas que adopta la vida en tanto sujeto de la política y, posteriormente, cómo estas formas son rehechas en el nivel subjetivo. Es en este marco de debates donde la pregunta conceptual y metodológica acerca de esa vida sujeto de la política, en tanto experiencia de vida, requiere una problematización específica y ensamblada, que es la que procuramos aquí.

La noción violencia hacia la vida es en esta doble línea una construcción analítica fruto del trabajo etnográfico, en el cual, a través de relatos y observaciones de campo, nos hemos encontrado con diversos episodios de esa experiencia de la violencia, tales como tiroteos entre bandas criminales -incluso a plena luz del día y en la puerta de las escuelas-, descargas ilegales de residuos y formación de basurales clandestinos a cielo abierto, homicidios violentos por armas de fuego, como también muertes relacionadas con las condiciones precarias de acceso a los servicios básicos. Todas situaciones que atraviesan la vida de los barrios, que imprimen marcas y recorren la vida de los sujetos. Los vecinos suelen referirse a estos fenómenos como situaciones en las cuales la salud, la integridad física y la propia vida se ponen en riesgo de manera directa, al mismo tiempo que los reconocen también como fenómenos relacionados con el accionar de poderes extraterritoriales a los barrios.

Es en este marco en el cual, alejados de la estigmatización y criminalización de la pobreza, entendemos resulta necesario el estudio de esas dinámicas tal como son vividas y se ensamblan
2. Para un mayor tratamiento del tema, ver LUCIANO MARTÍN MANTIÑ́́N (2018) "La violencia hacia la vida en contextos de pobreza urbana y degradación ambiental”. Doctorado en Antropología Social. Instituto de Altos Estudios Sociales. Universidad Nacional de San Martín. Disponible en http:// ri.unsam.edu.ar/bitstream/ handle/123456789/153/ TDOC_IDAES_2018_MLM. pdf?sequence $=1 \&$ is 
en la subjetividad. Se propone así que estas lógicas involucran la compleja trama de poder que atraviesa a la vida urbana contemporánea, lógicas que ocurren y sacan provecho de la situación de "excepción" (AGIER, 2012; GrINBERG, 2013) que caracteriza estos espacios urbanos. Situación de excepción que lejos de estar fuera de la ley, ocurre en la ley, y es justamente en ella o en sus bordes donde se despliegan y se realizan las tramas del gobierno de la población en la urbe metropolitana. Las formas de violencia y sus intensidades, sus grados de brutalidad, su "normalidad" y recurrencia no se distribuyen igualitariamente a través del trazado urbano, y definen aquello que OsBorne y Rose (1999) denominan los espacios que hay que evitar de la urbe contemporánea.

Considerando este marco de debates, en este artículo proponemos a modo de hipótesis lo siguiente:

1. La necesidad de realizar un estudio más allá de la estigmatización y mirada abyecta que suele recaer sobre estos espacios de la urbe, procurando comprender estas formas de violencia hacia la vida, atravesadas por las lógicas propias del ejercicio del poder en el marco de la urbe metropolitana (ChatterjeE, 2011; Rose, 1999; Arabindoo, 2011, DAs, 2003).

2. La violencia hacia la vida adquiere particularidades específicas en los contextos urbanos atravesados por la extrema pobreza y la degradación ambiental.

3. La violencia hacia la vida y las formas en que se vuelve cognoscible implican a la vida y sus formas en tanto sujetos de la política (DAs, 2003) y los modos en que son rehechas y significadas por los sujetos.

4. El trabajo de campo etnográfico es clave para la descripción y comprensión de cómo aparecen estas experiencias, cómo atraviesan la vida de los barrios y la subjetividad de sus habitantes. A través de los registros de campo, entonces, nos detendremos en el análisis de aquello que los sujetos expresan de su experiencia en los barrios, en directa relación con situaciones en las cuales sus vidas son violentadas. Sostenemos que el trabajo de campo etnográfico ofrece una multitud de oportunidades para explorar no solo las formas que asume la experiencia, sino también sus fisuras, disonancias y ambigüedades (GUBER, 2001; Rockwell, 2009; Althabe y Hernández, 2005; Peirano, 1995; Marcus, 2001).

El trabajo en terreno involucró una cantidad de actividades, entre las que podemos destacar visitas a hogares y familias, participaciones en reuniones e instancias barriales de diverso tipo, visitas y participación en proyectos escolares, entrevistas con vecinos, docentes, miembros de ONG que realizan actividades o están instaladas en los barrios, visitas a 
organizaciones barriales de vecinos, realización de historias de vida de vecinos. Clave para abordar el tema de esta investigación es haber adquirido cierta familiaridad y hasta amistad a lo largo de estos años con algunos de los vecinos de los barrios ${ }^{3}$. Esta circunstancia permite a estos interlocutores mayor confianza y soltura para referirse a cuestiones personales relacionadas con episodios de violencia y su consecuente sufrimiento, que de otro modo permanecerían por lo menos en gran parte vedadas para nosotros. El trabajo extendido en el tiempo también favorece el acercamiento comprensivo a ciertas dinámicas que hacen a la cotidianidad de los barrios y que, en esta investigación, benefician la reflexión acerca de la dimensión política de la violencia hacia la vida.

A continuación, tomando en esta ocasión solo algunos de estos múltiples registros, nos adentramos en la caracterización de las políticas sobre la vida y el violentamiento tal como son vividas y rehechas en el seno de la vida barrial.

\section{Rastreando las violencias: experiencias y significados}

La violencia y su experiencia no constituyen cuestiones fáciles de asir, y presentan varias dificultades. Con el objeto de sortear el problema de proyectar nuestros propios sentidos acerca de la violencia, es que procuramos una investigación etnográfica entendida como un diálogo amplio (GeERTz, 2006) con los sujetos directamente implicados. Ello con el objetivo de recuperar para el análisis algo de aquello que constituye la propia experiencia de los vecinos de los barrios. Por otra parte, partimos de una base de entendimiento según la cual ni la violencia, ni sus formas ni intensidades son características intrínsecas y "naturales" de los espacios donde desarrollamos nuestro trabajo. Se trata más bien de construcciones enraizadas en lógicas de poder que atraviesan dichos espacios y se expresan de formas particulares en ellos. Así, procuramos fugar de visiones estáticas de la violencia o naturalizada en sujetos y espacios, para procurar una visión relacional que ponga en juego su dimensión política, dimensión sin la cual esas formas de violencia no existirían y menos podrían explicarse. Esto, lejos de ser una premisa - como se podrá observar a lo largo de este artículo—, se desprende del propio trabajo de campo, en el cual nos encontramos con sujetos que saben de esas condiciones en las que viven, las hacen conscientes, las problematizan y las refieren en muchos de sus relatos; esa dimensión que aquí llamamos política y que atraviesa la cotidianidad de sus vidas.
3. Si bien el trabajo de campo que solventa este artículo fue realizado entre los años 2014 y 2017, el trabajo en terreno sobre diferentes temáticas que hacen a la experiencia de la vida en los espacios urbanos caracterizados por la pobreza y la degradación ambiental es llevado adelante desde el año 2009. 


\section{La violencia territorializada}

Una primera experiencia de la violencia que se puede mencionar está asociada al propio espacio territorial de la villa, espacio socialmente significado, significado que por otra parte más valdría expresar en plural, ya que puede presentar una gran variabilidad. Así, es posible identificar una experiencia propiamente espacial de la violencia que apunta a las significaciones asociadas por los vecinos de las villas a sus propios barrios; aunque por supuesto, están ineludiblemente relacionadas, es decir, en diálogo, con las significaciones que la sociedad y los mass media proyectan y producen sobre estos espacios. Estas significaciones están comúnmente asociadas a aquello que WacQuANT (2013, p. 40 y ss.) llama "estigma territorial", y que presenta como una de las "violencias de arriba" que sufren los habitantes de estos espacios urbanos relegados, por vivir en barrios "degradados" y "degradantes", etiquetados socialmente como lugares "que dan miedo". Los vecinos de los barrios en cuestión conocen por demás estas significaciones, que en sus vidas se traducen en una forma concreta de violencia hacia su orgullo y dignidad, violencia que cada quien sobrelleva a su modo.

Marta, una vecina de villa Esperanza (también conocida como "villa Corea"), de unos 55 años, brinda una primera aproximación al problema de la significación espacial de su barrio, en relación con la disputa por su propia nominación: "Vivo en el barrio villa Esperanza, conocido para todo el mundo como la Corea. En nuestro corazoncito queremos que sea villa Esperanza. Ya no más villa Corea”. Esta afirmación se debe a que cuando el barrio comienza a formarse alrededor de la década del 50 del siglo anterior, había dos bandas que se disputaban la posesión del territorio, y lo hacían con armas blancas y de fuego. Otro vecino nos relataba que incluso entre los bandos llegaban a quemarse los "ranchos" donde vivían los rivales para expulsarse unos a otros. El enfrentamiento debió de ser ciertamente violento, ya que el nombre de villa Corea hacía referencia a la guerra civil (1950-1953) que enfrentó a Corea del Norte y Corea del Sur, acontecimiento que los vecinos conocían a través de los medios de comunicación y que se libraba en los mismos años en que comenzaba a poblarse la zona.

Marta asocia el nombre "Corea" a una significación "negativa" con respecto al nombre "positivo" que representa para ella "Esperanza". "Corea" se asocia a una violencia, una guerra, externa, pero que servía para hablar, pensar, otra "guerra", una interna: "Villa Esperanza es porque es una cooperativa. La Corea es cuando este barrio se arma hace muchísimos años... de hecho, yo tengo 52 años y nací en este barrio" (Marta, vecina de Esperanza). 
Si "Corea” remite a una guerra, "Esperanza”, nombre que lejos de ser "neutro" en sí mismo engloba sentimientos y pensamientos "positivos", remite a una cooperativa, un grupo de vecinos que trabajan en conjunto y solidariamente por el bien común. Finalmente, un grupo salió victorioso en su intento de expulsar al otro y se consolidó en la zona organizando la mencionada cooperativa para lograr la titulación de los terrenos. Marta comprende esta significación y conoce su historia, pero la contrapone a otra asociada con el nombre de "Esperanza". Sin embargo, los años transcurridos desde aquellos primeros en la vida del barrio hasta la actualidad no lograron borrar en el uso corriente la voz "villa Corea", y de hecho la mayor parte de los vecinos con quienes hablamos tanto de "afuera" como de "adentro" del barrio se refiere a él de esa manera.

Otro aspecto de esta violencia territorializada lo podemos encontrar en los registros y relatos en que muchos vecinos expresaban un deseo de irse de los barrios que habitaban. Dicho deseo, por ejemplo, aparece en el siguiente escrito de un chico de trece años de la escuela de villa Carcova. Este relato junto con otros surge a partir de la propuesta de una actividad escolar, que tenía por consigna escribir historias sobre su barrio y su vida allí:

Me gusta jugar a la pelota, también me gusta venir al colegio. También me gusta la música de Romeo. Me gustaría tener una casa solo, cuando esté trabajando de algo. Me gustaría sacar de acá a mi mamá, mis hermanos, a mi tía y a mis sobrinos (cuento producido por estudiante de segundo año, 2014).

Ese deseo de irse, ese sacar de acá refiere a una experiencia de una violencia cotidiana, relacionada con las condiciones de vida propia de estos espacios y con las significaciones asociadas a ellos, significaciones que de diferentes formas se traspasan del espacio a los mismos vecinos, los llamados "villeros", los habitantes de las "villas". En el escrito de una chica de doce años de la misma escuela y en el marco de la misma actividad, la significación asociada al barrio es clara. Prevalece en este caso la resignación y la aceptación de vivir en un espacio como su villa, como la única opción posible:

Yo cuento esta historia de este barrio, es muy peligroso pero está más o menos bueno. La escuela está buena, hay muchas profesoras buenas. Mataron a muchos chicos de acá. En el zanjón tiraron mucha basura. Las plazas están re buenas. Anoche estaban tirando tiros, estaba durmiendo pero se escucharon muy fuertes. Es bravo este barrio pero es lo que hay (cuento producido por estudiante de segundo año, 2014). 
En cinco líneas los pensamientos de esta joven se precipitan y se mezclan, apareciendo varios elementos de la vida de los barrios que adquieren una particular relevancia en los últimos años y que se detallarán en el apartado siguiente: los tiroteos y las muertes violentas de menores. Otro elemento que aparece y hace a la vida "violentada" de los vecinos es la presencia de la basura, asociada por ellos - y con razón- a muchas de las enfermedades que se padecen y a la contaminación del ambiente. Este es un problema que viene de lejos, ya que en muchos casos se trata de asentamientos que se establecieron en la que fue la zona de esteros del río Reconquista, que en muchos casos eran utilizados como depósitos irregulares de basura. Cuando se comenzó a poblar la zona, los recién llegados debieron rellenar con escombros u otros materiales residuales el terreno inundable, y así poder levantar sus casas. Por su parte, los arroyos que llegan entubados transportan los desechos domiciliarios e industriales de la ciudad y atraviesan los barrios por varios sectores antes de llegar al río Reconquista. A esto se suma que muchos espacios en el interior de las villas son aún utilizados como basurales clandestinos por las industrias locales, cercanas o de otras partes de la ciudad. Así, es posible encontrarse con montañas de basura que son resultado de la disposición ilegal de los residuos urbanos en el barrio (Grinberg, Dafunchio, Mantiñán, 2012).

Se trata de una sucesión de situaciones en las cuales lo legal/ilegal atraviesa a los sujetos violentando de diversas formas sus vidas. Esas violencias a veces se presentan más difusas, otras más patentes, pero en muchos casos expresan dramáticamente problemáticas que vienen de lejos. Es decir, nos enfrentamos con personas marcadas por formas de violencia urbana, que con diferentes grados de intensidad atraviesan la vida de sus espacios vitales. Marta nos decía:

En el 51 habrá sido, calculale, más o menos. En esa época se vinieron [se refiere a su familia llegada desde el interior del país], y a los dos, tres meses, papá consigue [lugar] en esta villa. Era un asentamiento, eran todas casitas muy humildes pero de cartón, de madera, de chapa y lona. Eso era, eran pasadizos... mucha muerte, mucho tiro. Acá todos recordamos una infancia de tiros... (Marta, vecina de Esperanza, 2014).

En el caso concreto de villa Esperanza, esa "infancia de tiros” se debía principalmente a la disputa entre las bandas ya mencionada. Marta recuerda al barrio como "violento, violento", con muertes "por arma blanca”; "todos los días era alguien... y acá era un lugar donde había mucha gente que robaba", "siempre hubo muertes... en esa época sería entre bandos, entre bandas". Enseguida Marta menciona otro agente de violencia en y hacia la vida del barrio, 
esta vez directamente relacionado con el poder del Estado: "La policía... la policía siempre nos insultó". Estos relatos dan cuenta de una violencia vivida, una violencia urbana, política, que no padecemos quienes no nacimos ni vivimos en este tipo de espacios. Una violencia que sin lugar a dudas atraviesa las subjetividades, y que se expresa territorialmente. El deseo de irse del lugar propio o el solo hecho de pensar dicho lugar, referirse a él, se encuentra afectado visceralmente por dicha violencia, violencia enmarcada en la gubernamentalidad del espacio. La dimensión política de esta violencia no debe reducirse a la presencia de la policía mencionada por la vecina, sino que remite a algo mucho más profundo, relacionado con la misma constitución de estos espacios. Ya sea en la forma de disputa violenta por el territorio en manos de sujetos desposeídos que buscan un lugar donde poder hacer sus vidas, o en la necesidad de rellenar con residuos zonas de inundación para levantar la propia vivienda, en medio de los basurales de la ciudad, allí se expresan lógicas de poder diferenciales para con los sectores económicamente más vulnerables de la sociedad. Y esas lógicas no están asociadas a un Estado ausente, ayer u hoy, sino a un Estado, enmarcado dentro de un ejercicio de poder, que deja ser en los términos que de antemano prescribe.

\section{La muerte violenta. La excepción ordinaria}

Las formas de violencia que podemos caracterizar de más extremas de los últimos años remiten a muertes que ocurren en la forma de una excepción que deviene norma cotidiana, ordinaria. Se refieren a situaciones que, lejos de constituir una excepción, se vuelven modos ordinarios de la vida y de la muerte, relacionados con una problemática que se afianza en las villas entre fines del siglo anterior y los primeros años del nuevo. Marta nos lo comentaba de esta manera:

Ahí empieza ya el cuesta abajo del martirio de vivir en un barrio donde empezaba ahí... hasta entonces vos te sentabas en la vereda y hasta el día de hoy te podés seguir sentando en la vereda, solo que ya uno aprende a ver y a callarse... a veces, porque a veces peleamos mucho, con la policía o con los mismos pibes peleamos. Nos sentábamos afuera... noche de verano... que los chicos juegan en la vereda y el que empezó a vender [se refiere a la venta de droga en el barrio] acá en el barrio decía a los que le venían a comprar: “Ojo, ojo que está el televisor enchufado”. Esos éramos nosotros, los televisores enchufados. Y ¿qué pasa que viene gente? ¿Por qué viene gente? "Venden unas cosas que es droga, que te quedas loca, que no sé cuánto” (Marta, vecina de Esperanza, 2014). 
4. Nombre popular dado a los comerciantes de droga en los barrios.
En este relato Marta introduce una de las problemáticas que comenzarán a hacerse cada vez más acuciantes en las villas de la zona, y que consiste en la presencia de la droga y su comercio en los barrios, situaciones facilitadas por las condiciones de marginalidad y precariedad (Butler, 2010; Epele, 2010) que se ensamblan en las formas particulares que, proponemos, adquiere el gobierno de estos espacios urbanos.

Pasaron seis años y esto era un... no podías caminar, no podías caminar acá de la cantidad de coches que había (...) Era un desastre esto, un desastre (...) Y después de seis años era una locura, era una locura, era imposible vivir (Marta, vecina de Esperanza, 2014).

En una ocasión Luz, de villa Carcova, también nos hablaba de esta problemática. Nos comentó que ella había llegado al barrio en el año 2004, cuando "recién empezaba el tema de la droga" en ese barrio.

Los chicos y jóvenes del barrio también hablan a su manera de ese tema. El que sigue es otro de los relatos escritos por los chicos de la escuela media de Carcova en la actividad escolar ya mencionada:

Por Malvinas [se refiere a la calle del barrio] y la otra calle había un tiroteo entre tranzas y tranzas, y de un momento a otro salió una nenita de doce años y entre balas y balas paso la nena y le metieron un balazo por la cabeza y la dejaron inmóvil en el mismo lugar que quedo. Paso un señor con coche y los tranzas ${ }^{4}$ lo dejaron sin nada. Y gracias al señor del auto a la nena la pudieron tener unos segundos viva en el hospital hasta que murió de un derrame cerebral. Y por eso hicieron un mural en su nombre (cuento producido por estudiante de segundo año, 2014).

Una de las formas en que los vecinos parecen encontrar canales para clamar y reclamar por estas muertes, para "hacerlas presentes" y "no olvidarlas" — ante la imposibilidad de otras vías de reclamo válidas o factibles en otros contextos sociales- es la realización de murales o ermitas en conmemoración de los muertos. Estos son chicos muertos de forma violenta y significados como "inocentes". Otro escrito de un chico de la escuela dice: "Fue un día soleado cuando pensaron armar la casa en honor a los pibes que murieron, para que se sepa que siempre los vamos a recordar" (cuento producido por estudiante de segundo año, 2014). 
La memoria de los muertos se inscribe en los murales de los barrios y en los grafitis de la comisaría cada vez que los vecinos "estallan" por la muerte de alguno de sus chicos: "Enzo presente", reza un mural por un chico muerto en Carcova por una bala en octubre del año 2013. Una memoria que reactualiza las muertes, que se visibiliza, que pide justicia irrumpiendo en el espacio del barrio, o llegado el caso en la pared de la comisaría local, y reclama por el fin de estos episodios: "Justicia por Ivonne y seguridad para el barrio", "Ni una muerte más en Carcova”, se leía en los carteles realizados por los vecinos cuando se manifestaron en la comisaría por la muerte de Enzo. La frase ni una muerte más claramente remite a un tipo muy particular de ese fallecer. Si se vuelve grafiti y ese grafiti presenta el modo de la denuncia y la lucha es, justamente, porque son muertes en las cuales la excepción deviene norma, vida política ordinaria para estos espacios de la ciudad, pero que sus vecinos no se resignan a naturalizar.

La respuesta policial, ante los reclamos o denuncias de los vecinos, las marchas y protestas llega en forma de allanamientos en los barrios. Sin embargo, estos sucesos no provocan cambios significativos. Las frases que se repiten por su parte luego de los allanamientos son del siguiente tipo: "Se llevaron a un perejil", "levantaron a dos perejiles, pero los volvieron a largar”, para dar cuenta de que todo seguirá seguramente de igual modo y que la ley y lo ilegal en estos barrios ocurre de modos muy específicos. El actuar de la policía en este sentido acentúa la sensación o certeza de los vecinos cuando afirman la connivencia con el manejo de la droga en los barrios: "La gorra arregla", decía uno de los grafitis pintados en la pared de la comisaría de la localidad de Suárez cuando se reclamaba por la muerte de un chico, asesinado por un "transa". Cuando le preguntamos a Marta si ellos alguna vez habían podido denunciar estos problemas de violencia en el barrio, nos contestó:

Yo tuve un problema en esa época con uno de los pibes que era noviecito de mi sobrina, a quien le dije: "Bueno, basta”, porque el pibe había empezado a robar, a robar, a robar. Entraba por un lado, salía por el otro, entraba, salía [de la comisaría; se refiere a que quedaba detenido y en seguida volvía a estar libre]. Llegó un punto que ella no quería salir con él. Y el pibe vino, le puso un arma en la cabeza; entonces yo lo increpo y le digo que la deje porque lo iba a denunciar. "Ah bueno, andá, denunciame, te voy a dar vuelta vas a ver, te voy a dar vuelta”. Voy, lo denuncio en Suárez, lo voy a denunciar y te digo, me cruzo a comprar y él sale de adentro. Estaba adentro él. Y cuando llego a casa se reía y me decía: "Viste gila, viste, viste, hago lo que quiero en Suárez” (Marta, vecina de Esperanza, 2014). 
Este flagelo que vivían Marta y su sobrina llegó a su fin de otra manera: "otros transas" mataron al chico en cuestión. Pero esta situación estaba lejos de ser la peor experiencia que viviría Marta en villa Esperanza. Su hijo, Sergio, de 28 años, que acababa de salir en libertad por cometer un robo y también tenía problemas con el consumo de droga, fue asesinado por un transa local en el año 2006. Así relató Marta las últimas horas de su hijo, que en ese momento trabajaba vendiendo zapatillas de forma ambulante:

Sergio vende las zapatillas, tenía su boleto en el bolsillo para tomar el micro, ya era 22 de diciembre. Lo tomaba creo que a las 11: 10 de la noche, una cosa así - todavía tengo el boleto yo, estaba en su bolsillo-y va a entregar los últimos dos pares de zapatillas a su amigo que vive en la calle Latorre y Washington, dos parcitos, uno para el muchacho y uno para el hijito. Aparece Juan, le dicen el Negro [Marta me dirá después que Juan es "transa y ladrón”], y le dice a Sergio que lo va a hacer bailar "porque vos sos amigo del Pipo Villar", le dijo, "te voy a hacer bailar como lo hice bailar a él”. Y Sergio le dijo: "A mí no me metás porque él es mi amigo, pero yo no sé lo que vos tenés con él”. No sé... hay testigos, siete testigos hay de esto, uno de ellos es el primo de él. Y el chico este, Juan, se va, y él queda esperando sentado con los pibes que venga el amigo de la fábrica (...) Y bueno, se va, vuelve con un coche, con un chaleco antibalas de la policía federal y con dos revólveres, dos nueve milímetros. Dieciséis balas cada uno y le pegó todas menos tres [los ojos de Marta se humedecen, pero continúa con su relato]. Todas a él. Con la primera cae Sergio, por la espalda le dio, cae boca abajo, por la espalda le dio todas las demás. Lo fusiló, es lo que me dijeron en la fiscalía (Marta, vecina de Esperanza, 2014).

Tras unos meses en que Marta buscó infructuosamente la forma de que el asesino de su hijo fuera apresado, este sujeto fue detenido, pero no por matar a su hijo, sino por matar a un policía. Ninguno de los testigos del asesinato de Sergio quiso declarar en contra del asesino, porque estaban amenazados por la familia de Juan. Según Marta, la familia de Juan también hizo algún "arreglo con la policía”, porque dice saber que pronto estará en libertad, y teme que al salir de la cárcel aún tome represalias contra ella, como si el asesinato de su hijo no fuese ya suficiente dolor con el que vivir.

Respecto de los tiroteos en los barrios, nunca fuimos testigos directos de ninguno, pero en diferentes ocasiones nos han relatado varios episodios de ellos, generalmente entre bandas que se dedican a manejar el comercio de la droga en los barrios. Se trata de relatos que 
hemos escuchado en la misma escuela barrial de Carcova. De hecho, la escuela ha quedado bajo fuego en varias oportunidades, por lo cual sus autoridades en reiteradas ocasiones pidieron la presencia de la gendarmería en la puerta, sin obtener el resultado esperado. Es cosa sabida por todos que detrás de la escuela vive uno de los principales transas locales. En un ciclo escolar esta situación se presentó tan compleja para la continuidad de la vida de la institución, que esta debió cerrar sus puertas y terminar las últimas semanas de la primera mitad del año dictando sus clases en otra escuela, ubicada a unas cinco cuadras fuera de la villa en cuestión.

En este caso de las muertes violentas tampoco debemos reducir el lugar del poder y sus tramas a las menciones que se hacen acerca de la policía. Las lógicas de poder atraviesan visceralmente y diferencialmente estos espacios de la ciudad y a sus habitantes. Los tiroteos y las muertes ocurren porque se inscriben dentro de los límites que dichas lógicas establecen para que allí ocurra la vida. Los vecinos saben más o menos conscientemente que no se trata de vivir en un lugar de por sí violento; esa violencia no está presente como un atributo de su espacio, sino en movimiento, en relación política con el afuera; no la naturalizan, por eso la denuncian, por eso se manifiestan en la comisaría y hacen ermitas. El hecho de que chicos puestos en la tarea de hablar simplemente de su vida en su barrio mencionen el asesinato de pares cuando otros chicos podrían hablar de paseos, deportes o familia nos habla de una excepción vuelta ordinaria, de algo que se denuncia pero que se mezcla en la cotidianidad con el juego, la escuela y las plazas. Y entre medio de estas situaciones y experiencias de vida se avizoran las tramas políticas que constituyen diferencialmente los espacios, que permiten o prohíben ciertas formas de violencias, que regulan también sus intensidades y frecuencias.

\section{Palabras finales}

A largo de este artículo nos ocupamos de modos de la violencia procurando, a través de la descripción etnográfica, adentrarnos en la experiencia de la violencia tal como es narrada, vivida, sentida y pensada por habitantes de aquellos barrios que se caracterizan por la extrema pobreza urbana y la degradación ambiental. Si bien la referencia a la violencia en estos barrios no es algo nuevo, entendemos que a través del trabajo de campo hemos podido adentrarnos en la trama de esa violencia vista desde una perspectiva diferente. Se trata de aquellas formas que involucran asesinatos, tiroteos, y que están acompañados por 
la impunidad en la gran mayoría de los casos y la connivencia, elementos que se configuran como parte de los modos de hacerse presente el Estado en estos espacios de la urbe. Se trata de una experiencia de la violencia que se vive en las villas y que es muy diferente de la que viven los vecinos de otros sectores de la ciudad.

Claramente la violencia hacia la vida en la ciudad no se distribuye de forma igualitaria a través del trazado urbano, tal como era remarcado en el inicio; tampoco sus intensidades y sus recurrencias. Así en la ciudad existen formas diferenciales de vivir, transitar y significar la violencia hacia la vida, y en las llamadas villas recaen sus formas más crudas. El lugar que al Estado históricamente y en todas sus formas — no solo en cuanto policía— le toca en esta configuración de la experiencia es un dato clave para entender los modos en que la violencia se vive a diario y cómo aquellas formas de la violencia son vividas, pensadas y significadas por los vecinos de estos barrios.

A través del relato etnográfico hemos procurado mostrar algunos modos singulares por los que ocurren esas violencias, violencias territorializadas donde la vida queda en permanente entredicho. Ello a través de artificios minuciosos que resultan en la condensación y materialización en el espacio de unos mecanismos y relaciones de poder, que arrojan a la población a hacer sus vidas en una situación de permanente exposición. Hay algo de cotidianidad en la excepción que parece instalarse en la vida de los barrios, que en los relatos, especialmente en aquellos producidos por los jóvenes en la escuela, adquiere una virulencia y densidad muy particular. Una violencia que se encarna en la vida diaria y permite encontrarse con los modos que presenta la gestión de la vida, los modos y relaciones de poder en sus formas ordinarias y materiales. Ahora, se trata de un tipo de excepción que no ocurre en la suspensión de la ley, sino más bien en la ley que el poder impone o como parte de ella. No se trata de un "al margen" de la ley, sino más bien que todo esto ocurre en su propio margen, dentro de ella y sus mecanismos.

A través de la descripción densa (GEERTz, 2006) hemos procurado perfilar las experiencias de violencia y algunas de las significaciones que los vecinos asocian a ellas. La experiencia de la violencia adquiere una particularidad propia en la vida cotidiana de estos espacios urbanos, espacios relegados que parecerían "tierra de nadie", donde todo puede ocurrir, aunque en realidad debieran entenderse como espacios regulados y controlados por lógicas particulares de poder. Sus responsabilidades y alcances trascienden claramente los límites 
físicos de los propios barrios en cuestión, y permiten comprenderse cuando las pensamos como formando parte de una imagen completa, que remite a las formas que asumen las relaciones de poder en la urbe contemporánea.

\section{Referencias bibliográficas}

AGIER, Michel (2012). El biopoder a prueba de sus formas sensible. En Política y Sociedad, Vol. 49, Nro. 3: 487- 495. Madrid: Universidad Complutense de Madrid.

ALTHABE, Gerard y HERNÁNDEZ, Valeria (2005).Implicación y reflexividad. En Hernández et al. (comps.), Etnografías Globalizadas, Pp. 71 a 90. Buenos Aires: Ediciones SAA.

ARABINDO0, Pushpa (2011). Rhetoric of the 'slum', City: analysis of urban trends, culture, theory, policy, action. En: Routledge Taylor \& Francis Group, 15 (6), 636-646. Recuperado el 30 de marzo de 2017, de http://dx.doi.org/10.108 $0 / 13604813.2011 .609002$.

AUYERO, Javier y BERTI, María (2013). La violencia en los márgenes. Una maestra y un sociólogo en el conurbano bonaerense. Buenos Aires: Katz Editores.

AUYERO, Javier (2001). La política de los pobres. Las prácticas clientelistas del peronismo. Buenos Aires: Manantial.

BERMÚDEZ, Natalia (2008). Merecer la muerte. Una antropología sobre las moralidades y las prácticas políticas en torno a las muertes violentas (Córdoba- Argentina) En: IX Congreso Argentino de Antropología Social. Facultad de Humanidades y Ciencias Sociales. Universidad Nacional de Misiones, Posadas.

BOURGOIS, Pierre (2002). El poder de la violencia en la guerra y la paz. En Apuntes de investigación del CECyP, año VI, nro. 8, pp. 73-98. Facultad de Ciencias Sociales, Universidad de Buenos Aires. Buenos Aires.

BUTLER, Judith (2010). Marcos de guerra. Las vidas lloradas México: Paidós.

CHATTERJEE, Partha (2011). La política de los gobernados. En Margarita Chaves y Juan Felipe Hoyos, Grupo de Antropología Social de la Revista Colombiana de Antropología. Volumen 47 (2), julio-diciembre 2011. Instituto Colombiano de Antropología.

CURUTCHET, Gustavo; GRINBERG, Silvia; GUTIÉRREZ, Ricardo (2012). Degradación ambiental y periferia urbana: un estudio transdisciplinario sobre la 
contaminación en la Región Metropolitana de Buenos Aires. En Ambiente \& Sociedade Vol. 15 no. 2 mayo/agosto. Associação Nacional de Pós-Graduação e Pesquisa em Ambiente e Sociedade. Sao Paolo.

DAS, Veena (2003). Trauma and Testimony. Implications for political community. En: Anthropological Theory. Vol. 3. Academia Suiza de Ciencias Sociales y Humanas.

EPELE, María (2010). Sujetar por la herida. Una etnografía sobre drogas, pobreza y salud. Buenos Aires: Paidós.

GARRIGA ZUCAL, José y NOEL, Gabriel (2010). Notas para una definición antropológica de la violencia: un debate en curso. En: PUBLICAR en Antropología y Ciencias Sociales; pp. 101-126. Revista del Colegio de Graduados en Antropología de la República Argentina. Buenos Aires.

GEERTZ, Clifford (2006). La interpretación de las culturas. Barcelona: Editorial Gedisa, SA.

GRINBERG, Silvia (2013). Pedagogía de las competencias y gubernamentalidad en las sociedades de gerenciamiento. La formación: entre la reinserción y la abyección. En Revista textos. Vol.8,N. ${ }^{\circ}$ 18. ISSN 0123-8957. Bogotá: Pontificia Universidad Bolivariana de Medellín.

GRINBERG, Silvia; DAFUNCHIO, Sofía; MANTIÑÁN, Luciano Martín (2013). Biopolítica y ambiente en cuestión. Los lugares de la basura. Revista Horizontes Sociológicos. Año 1, nro. 1, mayo-junio. ISSN 2346-8645. Asociación Argentina de Sociología. Buenos Aires.

GRINBERG, Silvia; GUTIÉRREZ, Ricardo; MANTIÑÁN, Luciano Martín (2012). La comunidad fragmentada: Gubernamentalidad y empoderamiento en territorios urbanos hiperdegradados. En: Revista Espacios nueva serie, Estudios de Biopolítica N. ${ }^{\circ}$ 7: 154-172. ISSN 1669-8517. UNPA, Universidad Nacional de la Patagonia Austral.

GUBER, Rosana (2001). La etnografía. Método, campo y reflexividad. Bogotá: Grupo Editorial Norma.

LEWIS, Oscar (1983). La vida. Barcelona: Grijalbo.

MARCUS, George (2001). Etnografía en/del sistema mundo. El surgimiento de la etnografía multilocal. Alteridades 11(22): 111-127. Departamento de Antropología, Universidad Autónoma Metropolitana, México.

MERKLEN, Denis (2005). Pobres ciudadanos. Las clases populares en la era democrática (Argentina, 1983-2003). Buenos Aires: Ed. Gorla. 
OSBORNE, Thomas y ROSE, Nikolas (1999). Governing Cities: Notes on the Spatialisation of Virtue”. En: Environmental and Planning D, Society and Space, 17, 737760.

PEIRANO, Mariza (1995). A favor da etnografía. Rio de Janeiro: Relume Dumará.

PRÈVÔT SCHAPIRA, Marie-France (2001). Fragmentación espacial y social: Conceptos y realidades. En Perfiles Latinoamericanos, Nro. 19. Facultad Latinoamericana de Ciencias Sociales, México.

RATIER, Hugo (1985). Villeros y villas miseria. Buenos Aires: Centro Editor de América Latina.

ROCKWELL, Elsie (2009). La experiencia etnográfica. Historia y cultura en los procesos educativos. Buenos Aires: Paidós.

ROMERO, José Luis (1986). Latinoamérica: Las ciudades y las ideas. Buenos Aires: Siglo Veintiuno Editores.

ROSE, Nikolas (1999). Powers of Freedom. Reframing political thought. United Kingdom, Cambridge University Press.

SCHEPER-HUGHES, Nancy (1993). La muerte sin llanto. Violencia y vida cotidiana en Brasil. Barcelona: Ed. Ariel.

TORRE, Juan Carlos y PASTORIZA, Elisa (2002). La democratización del bienestar. En: Torre, J. C. (Dir.) Nueva Historia Argentina, Tomo VIII: Los años peronistas (1943-1955). Buenos Aires: Sudamericana.

WACQUANT, Louis (2013). Los condenados de la ciudad. Gueto, periferias y estado. Buenos Aires: Siglo XXI Editores. 